\title{
Diálogos da Universidade com a Comunidade Escolar sobre Educação para a Sustentabilidade
}

\author{
Dialogues of the University with the Scholar Community \\ about Education for Sustainability
}

\section{RESUMO}

O curso Diálogos da Universidade com a Comunidade Escolar sobre Educação para a Sustentabilidade foi realizado de agosto a novembro de 2013 junto a escolas rurais da rede pública de Ibiúna, São Paulo. Contou com 21 participantes, entre professores, funcionários administrativos, diretor, merendeiras e encarregados de serviços gerais. Foi elaborado por doutorandas e professores do Laboratório de Pesquisa e Práticas em Educação e Sustentabilidade da Universidade de São Paulo (LAPPES-USP), com reconhecimento da Faculdade de Educação (FE-USP) e apoio da ONG Ação da Cidadania - Comitê Ibiúna-SP. Para cumprir o objetivo de promover a inserção da sustentabilidade no cotidiano escolar, a metodologia do curso, com oito encontros, envolveu exposição teórica, atividades dialogadas, troca de experiências e trabalho de campo baseados no referencial teórico-metodológico da Aprendizagem Social centrada na construção contextualizada e coletiva de conhecimento por meio de oportunidades educacionais participativas. Os temas foram "Educação para sustentabilidade", "Cultura e patrimônio local e regional", "Saúde pública e saneamento" e "Participação e aprendizagem social”. Os resultados mostraram êxito no diálogo entre universidade e comunidade escolar para uma práxis educativa para a sustentabilidade, na metodologia, cujas práticas dialógicas apoiaram a construção coletiva de propostas de intervenção, e na aprovação do curso para a rede escolar da cidade no $2^{\circ}$ semestre de 2014. Palavras-chave: Educação. Sustentabilidade. Aprendizagem Social. Participação.

\section{ABSTRACT}

The course Dialogues of the University with the Scholar Community about Education for Sustainability was conducted from August to November 2013, with the rural public schools of Ibiúna, São Paulo. It included 21 participants: teachers, administrators, director, cooks and general services. It was planned by doctoral students and professors

Samia Nascimento

Sulaiman, Maria

Aparecida Pimentel

Toloza Ribas,

Renata Ferraz

de Toledo e Ana

Cristina Chagas dos

Anjos

Universidade de São Paulo. Faculdade de Educação, São Paulo, Brasil

Pedro RoBerto Jacobi Universidade de São Paulo, Faculdade de Educação e Instituto de Energia e Ambiente, São Paulo, Brasil 
from Laboratory of Research and Practices in Education and Sustainability, from University of São Paulo (LAPPES-USP), with recognition of the Faculty of Education and support from NGO Ação da Cidadania - Comitê Ibiúna/SP. To fulfill the objective of promoting the integration of sustainability into everyday school life, the methodology of the course, with 8 meetings, involving theoretical exposition, dialogued activities, exchanges of experiences and field work, based on theoretical and methodological framework of the Social Learning focused on contextual and collective construction of knowledge through participatory educational opportunities. The topics were Education for Sustainability; Local and Regional Culture and Heritage; Public Health and Sanitation; Participation and Social Learning. The results indicated successful dialogue between university and schoolar community for an educational praxis for sustainability, methodology whose dialogic practices supported the collective construction of intervention proposals and the approval of the course to the school system of the city in the 2 nd semester of 2014.

Keywords: Education. Sustainability. Social Learning. Participation.

\section{INTRODUÇÃO}

O Laboratório de Pesquisa e Práticas em Educação e Sustentabilidade (LAPPES-USP) envolve docentes, pesquisadores e estudantes de várias unidades da Universidade de São Paulo e desenvolve um enfoque interdisciplinar na abordagem de temas relacionados à educação, meio ambiente e cidadania. Criado em 2012 a partir do grupo TEIA-USP, sediado na Faculdade de Educação (FE-USP) desde 2005, o LAPPES é atualmente um dos espaços de produção de conhecimento e disseminação de propostas de intervenção socioeducativas do Programa de Pós-Graduação em Ciências Ambientais do Instituto de Energia e Ambiente (PROCAM-IEE-USP). Em 2013, três pós-graduandas e dois professores do Laboratório elaboraram, coletivamente, um curso de extensão para promover o diálogo entre a pesquisa acadêmica sobre educação para a sustentabilidade e o cotidiano escolar, aprovado pela Comissão de Cultura e Extensão da FE-USP, que expediu os certificados validados pela Universidade de São Paulo aos participantes. O curso contou ainda com o apoio de dois monitores, um aluno da graduação de Geociências (IGc-USP) do Projeto Aprender com Cultura e Extensão 2013/2014 e uma aluna de Engenharia Ambiental da Universidade de Sorocaba (UNISO) envolvida com a ONG parceira.

Os profissionais da educação de escolas municipais rurais da cidade Estância Turística de Ibiúna foram o público-alvo do curso de 30 horas, realizado no $2^{\circ}$ semestre de 2013. A escolha deveu-se pela viabilidade de diagnóstico prévio e a relevância do curso frente às demandas e iniciativas locais sobre os temas ambientais. Ibiúna, município paulista da região de Sorocaba, está localizada em área de manancial e reserva florestal. Em seu território encontra-se o Parque Estadual Jurupará, uma Unidade de Conservação de Proteção Integral para preservar a natureza em áreas com pouca ou nenhuma ação humana, e a Área de Proteção Ambiental Itupararanga, uma Unidade de Conservação de Uso Sustentável [4] que associa a conservação da natureza com o 
uso sustentável de parcela de seus recursos naturais. Possui vasta rede hídrica, sendo cabeceira de importante bacia hidrográfica dos rios Sorocaba e Médio Tietê.

O município tem base econômica na agricultura, seguida pelo comércio local, com expressiva população flutuante nos finais de semana e feriados por conta das visitas a chácaras, pousadas e condomínios. Dos seus 71 mil habitantes (Censo de 2010), 65\% vivem em área rural que concentra problemas de saneamento básico, já que a rede de serviços de saneamento, assim como de saúde, está concentrada na sede do município, o que provoca impactos negativos socioambientais e de saúde pública. Essas características já colocam o tema ambiental e a questão da sustentabilidade como essenciais à constituição e ao desenvolvimento da cidade.

$\mathrm{Na}$ área da educação, existem escolas municipais de educação infantil e ensino fundamental até o quinto ano em Ibiúna. Escolas estaduais atendem do sexto ao nono ano do ensino fundamental e o ensino médio. A maioria das escolas localiza-se na zona rural e algumas delas funcionam com salas multi-seriadas, com alunos de anos escolares distintos na mesma sala e com o mesmo professor. Em algumas escolas menores, funcionários acumulam outras funções, como a de merendeiro e auxiliar de serviços gerais. Apesar do desafio desse cenário, essas salas colocam a oportunidade de processos de ensino-aprendizagem coletivos e dialogados [9].

Os 21 participantes do curso não se restringiram aos professores. Participaram também funcionários administrativos, diretor, merendeiras e auxiliares de serviços gerais, definidos como profissionais da educação devido ao entendimento de que a educação para a sustentabilidade é um processo de construção coletiva de conhecimento e ação que envolve todo o espaço escolar e se desenvolve por meio de contextos de diálogo de opiniões e pontos de vista de todos os envolvidos, apoiando-se no referencial teórico-metodológico da aprendizagem social.

O conceito de aprendizagem social (social learning) [11] tem um longo percurso histórico com diferentes abordagens e contextos. No campo da psicologia behaviorista ou comportamentalista, estava relacionada a um tipo de aprendizagem individual possível por meio da observação e/ou interação com o contexto social [1]. No campo da gestão ambiental, a aprendizagem social apoia-se no crescente entendimento de que a diversidade de opiniões dos diferentes atores envolvidos (stakeholders) da questão ambiental (planejadores, organizações não governamentais, políticos, etc.) e as diversas fontes de conhecimento da área (pesquisa científica, povos indígenas, donos de terras, etc.) podem, em diálogo e interação, subsidiar tomadas de decisão com maior qualidade e validade social [12]. Com base nesse referencial teórico-metodológico, o curso estruturou-se em processos comunicativos multidialogados para troca de experiências, negociações e construção coletiva de conhecimento baseados nas questões e opiniões originadas do contexto local e direcionadas a ele.

\section{O DESENVOLVIMENTO DO CURSO: FUNDAMENTOS TEÓRICOS E DIDÁTICOS}

Com base no referencial teórico-metodológico da aprendizagem social, o curso 
concentrou-se em atividades dialogadas e práticas com algumas intervenções de exposição teórica. Além de propor a construção coletiva de conhecimento e a articulação dos saberes dos participantes, buscou-se evidenciar os desafios e as potencialidades locais para desenvolver a educação para a sustentabilidade de acordo com os seguintes objetivos:

1. Abordar os fundamentos teóricos e metodológicos da educação para sustentabilidade de forma a permitir a compreensão da natureza complexa do meio ambiente, resultante das interações dos seus aspectos biológicos, físicos, sociais e culturais;

2. Colaborar na formação de agentes multiplicadores para o processo de sensibilização da comunidade local para o seu papel co-responsável nas ações de proteção do patrimônio cultural e ambiental local;

3. Apresentar e aplicar práticas pedagógicas participativas e de aprendizado coletivo, buscando promover um espaço de troca de informações e experiências e de construção de conhecimentos;

4. Realizar atividades de diagnóstico participativo sobre a realidade local, estimulando o exercício da cidadania de forma individual e/ou coletiva no que diz respeito ao meio ambiente, políticas públicas, saúde, conservação de recursos naturais e culturais, entre outras problemáticas socioambientais.

Em oito encontros, realizados nas manhãs de sábados de agosto a novembro de 2013, foram abordados os seguintes temas: "Educação para sustentabilidade", "Cultura e patrimônio local e regional”, "Saúde pública e saneamento", "Sustentabilidade, participação e aprendizagem social”, com realização de "Workshop" de elaboração de projetos e trabalho de campo com "Mapeamento socioambiental e estudo do meio", finalizando com uma "Avaliação do curso" e definição de "Propostas futuras".

\section{CONSTRUINDO O DIÁLOGO}

O primeiro encontro, "Educação para sustentabilidade", abordou os conceitos de sustentabilidade, participação e aprendizagem social. Inicialmente questionou-se quais as expectativas para o curso para os participantes, cujas respostas podem ser exemplificadas com "Gostaria que os conhecimentos que vamos adquirir no curso pudessem nortear mais o trabalho do professor em sala de aula e no dia a dia", ou "Caminhar todo mundo junto". Buscou-se descontruir a noção de "transmissão de conhecimento" para enfatizar a abordagem participativa e coletiva do curso. Primeiramente desenvolveu-se uma apresentação dialogada sobre a realidade ambiental do século XXI com escassez e má distribuição de água, ameaças à biodiversidade, desmatamentos, padrões de produção e consumo insustentáveis, uso insustentável dos recursos naturais, produção excessiva de lixo, mudanças climáticas e acesso desigual aos recursos 
naturais e pobreza. Propôs-se uma discussão e reflexão sobre a perspectiva da "sociedade de risco" [2] em que vivemos e a necessidade de tomada de consciência sobre os impactos dos problemas ambientais e de como a sociedade pode gerir os riscos inserindo os desdobramentos do desenvolvimento sustentável para conciliar proteção ambiental com justiça social e eficiência econômica [20], assim como atender às demandas por educar para a sustentabilidade com base no diálogo e na participação por meio de contextos de aprendizagem social [13].

Para colocar em prática a perspectiva de aprendizagem social, realizou-se a atividade do painel integrado $[16,24]$, uma ferramenta participativa de diagnóstico de representações sociais dos participantes sobre cinco temas a serem tratados no curso: educação, sustentabilidade, participação, saúde e patrimônio. Divididos em cinco grupos, cada um recebeu um papel kraft com uma pergunta, como “o que é educação?”. Após discussão interna, o grupo respondia à pergunta e trocava seu papel com outro grupo que havia respondido a outra pergunta, como “o que é sustentabilidade?”. Nessa rodada, cada grupo, para elaborar a sua resposta, também consideraria a já dada por outro grupo. Finalizando a resposta, novamente eram trocadas as perguntas entre os grupos, que nessa $2^{\circ}$ rodada levariam em consideração as duas respostas anteriormente dadas, além da opinião do grupo. Esse processo organizou-se em quatro rodadas, até que todos os grupos respondessem as perguntas referentes aos cinco temas do curso. Com cada papel kraft exposto na parede (Figura 1), foram sendo reconhecidas as palavras em comum nas respostas dos grupos, assim como as díspares, e o mediador apresentou explicações teóricas sobre as representações que se desenvolvem em relação a cada tema e como elas podem ser positivas para se pensar a questão ambiental e definir os caminhos a serem trabalhados no curso, tendo como pergunta-tema "De que educação para a sustentabilidade estamos falando?”.
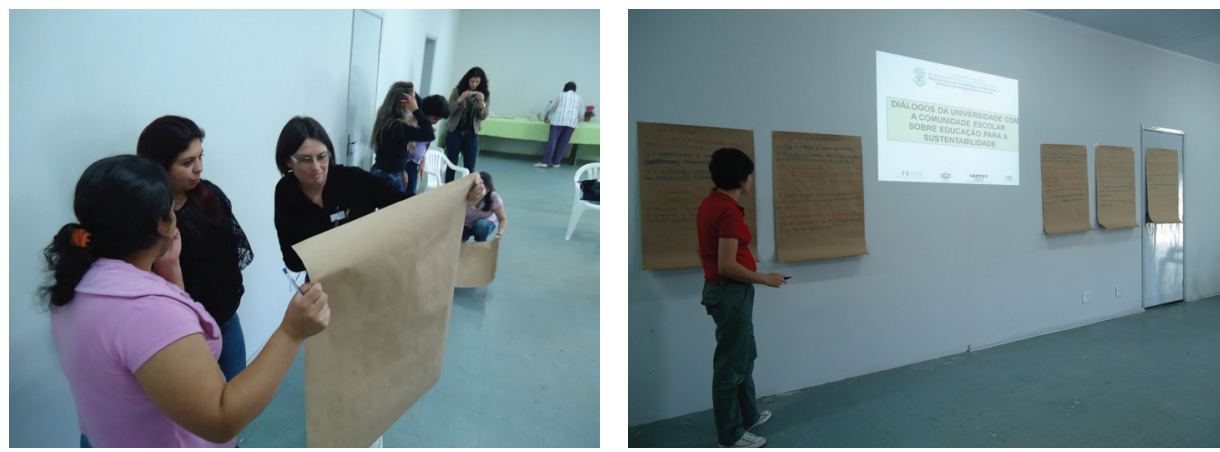

\section{RECONHECENDO E VALORIZANDO RECURSOS LOCAIS}

O segundo encontro, "Cultura e patrimônio local e regional”, buscou resgatar a memória e dar relevância à história e patrimônio de Ibiúna. Por meio da atividade prática "Histórias e memórias: narração de experiências a partir de objetos" [15], cada participante escolheu um objeto disposto numa mesa (Figura 2) e deveria atribuir-lhe
Figura 1 - Dinâmica do painel integrado para levantamento de representações sociais: à esquerda, cada grupo responde as questões propostas; à direita, a mediadora articula as respostas. 
nome e justificar sua escolha. A atividade possibilitou o resgate de histórias familiares, de lembranças da infância, de reflexões sobre o município de Ibiúna e de hábitos e costumes atualmente esquecidos, também permitiu discutir o sentido de patrimônio como "um conjunto de bens materiais (tangíveis) e imateriais (intangíveis) identificados como significativos para um determinado grupo, comunidade ou sociedade" [8]. Foram tratados conceitos de patrimônio, patrimônio arqueológico, arqueologia e educação patrimonial [22], que desencadeou a atividade prática sobre mapa patrimonial, uma atividade artística para representação gráfica do patrimônio da cidade. Os participantes se reuniram em seis grupos, cada um definiu uma ou mais imagens e desenharam em papel cartolina (Figura 2). Ao final, compartilharam os resultados e discutiram a relevância de se pensar e evidenciar os recursos materiais e imateriais do município para se pensar em educar para a sustentabilidade. Foi solicitado que os participantes trouxessem fotografias do município para o próximo encontro.

Figura 2 - Valorização da memória: à esquerda, o uso de objetos para levantamento de histórias e memórias pessoais e locais; à direita, um Mapa Patrimonial de Ibiúna.
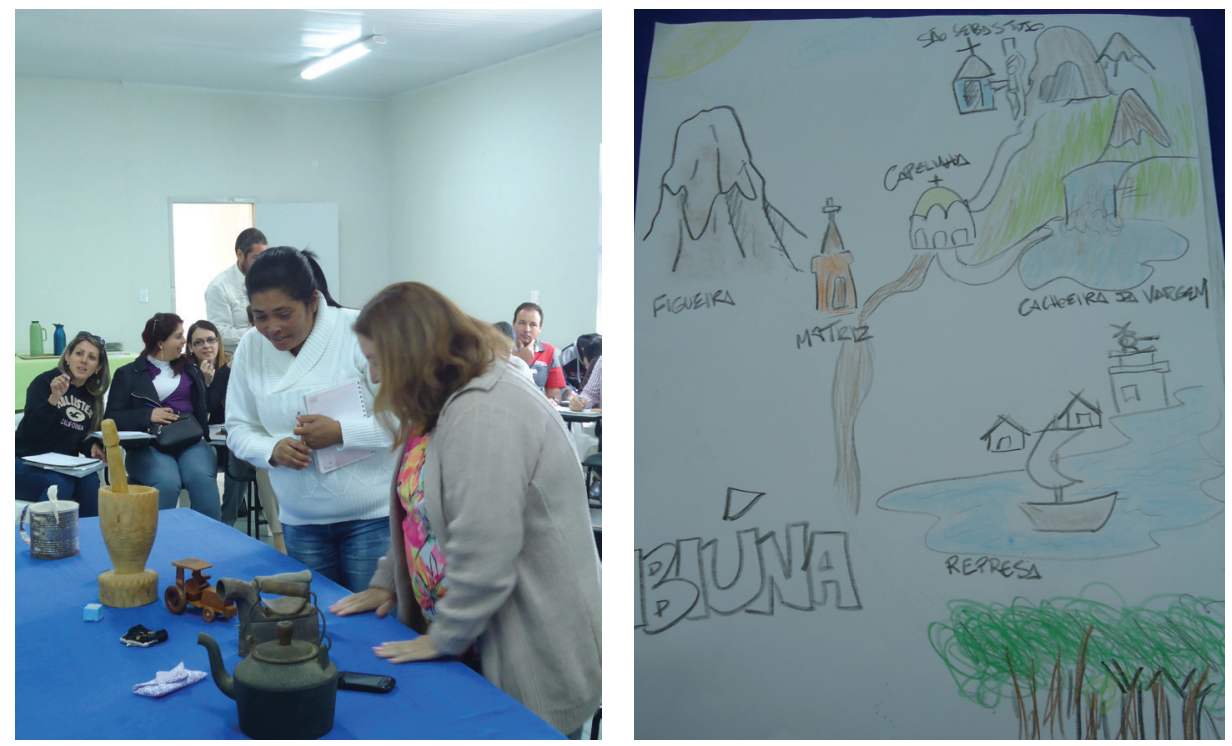

O terceiro encontro, "Saúde pública e saneamento", iniciou-se com discussões da relação meio ambiente-sociedade a partir dos mapas patrimoniais do encontro anterior. Foram introduzidos resultados parciais de uma pesquisa de doutorado realizada na bacia hidrográfica do ribeirão da Vargem do Salto, compreendendo cinco bairros rurais de Ibiúna, para a discussão sobre saneamento local [7] e suas questões legais [3], assim como sobre a universalização do acesso aos serviços e controle social como princípios fundamentais dos serviços públicos de saneamento. O passo seguinte foi a elaboração de painel fotográfico com o material que os participantes disponibilizaram. As fotos foram agrupadas por semelhança de temas em cinco painéis, com os seguintes questionamentos: "Por que acontece isso?" e "Que possíveis soluções?”. Os painéis foram analisados e discutidos pelo grupo todo e foram colocadas três questões para serem debatidas no encontro seguinte: "Como a educação pode fortalecer 
o diálogo entre comunidade escolar, sociedade e poder público local?”, “Como tenho contribuído nesse processo?” e "O que podemos fazer em nossas escolas em prol de ações mais sustentáveis?”.

O quarto encontro, "Sustentabilidade, participação e aprendizagem social”, desenvolveu a reflexão sobre o papel da aprendizagem social para o diálogo, o reconhecimento das interdependências dos atores sociais, a interação entre os atores, a transparência e confiança, a auto-reflexão crítica e a percepção compartilhada dos problemas e soluções [10]. A temática foi subsidiada pela dinâmica de jogo de papéis (role-play) [17] sobre a problemática dos resíduos sólidos. Os participantes foram divididos em grupos para que representassem possíveis atores envolvidos na questão: prefeitura, universidade, escolas, moradores, catadores de materiais recicláveis e empresa de coleta de lixo. A dinâmica, além de envolver os participantes com a temática, colocou-os assumindo papéis (responsabilidades, interesses, pontos de vista) do outro, permitindo entender e vivenciar os diferentes conflitos entre as partes, além de verificar que diálogo e pactos são possíveis e podem trazer resultados e ações concretas, retomando o pensamento de Paulo Freire de que "a primeira condição para que um ser possa assumir um ato comprometido está em ser capaz de agir e refletir” [6].

Dentro dessa perspectiva de valorização dos recursos e potenciais locais, durante os intervalos dos encontros foi oferecido um cardápio diferenciado de lanches e saladas, trocando os produtos industrializados por produtos naturais da cidade, sendo alguns desconhecidos do repertório alimentar de parte dos participantes. Evitou-se a utilização de copos, talheres e pratos descartáveis, com objetivo de geração mínima de resíduos.

\section{CONSTRUINDO PERSPECTIVAS E SOLUÇÕES COLETIVAMENTE}

O quinto encontro, "Workshop", teve como objetivo retomar os conteúdos vistos e criar oportunidades para definir atividades que pudessem ser inseridas nas atividades pessoais e profissionais dos participantes. Com base em três perguntas-chave, "O que construímos até agora?”, "O que relacionamos com as nossas práticas?” e "O que podemos empreender?”, houve a retomada dos conteúdos e experiências vividas nos encontros anteriores, o levantamento das atividades realizadas e o reconhecimento de possibilidades de incorporação dessas novas ideias nas práticas cotidianas, além da construção coletiva de propostas educativas para cada área de atuação. Motivados por um vídeo sobre o educador Tião Rocha, de Minas Gerais, na sua atuação no Centro Popular de Cultura e Desenvolvimento (CPCD), os participantes, reunidos de acordo com sua área de atuação (merendeiras, professores de sala seriada, funcionários administrativos, auxiliares de serviços gerais), iniciaram a elaboração de cinco projetos (Tabela 1 ). 
Tabela 1 - Projetos elaborados coletivamente pelos participantes do curso

PROJETOS DE EDUCAÇÃO PARA A SUSTENTABILIDADE

\begin{tabular}{|c|c|c|}
\hline TíTULO & OBJETIVO & PÚBLICO-ALVO \\
\hline $\begin{array}{l}\text { Natureza e } \\
\text { matemática }\end{array}$ & $\begin{array}{l}\text { Oferecer condições de } \\
\text { aprendizagem matemática } \\
\text { no plantio de verduras }\end{array}$ & $\begin{array}{l}\text { Alunos do } 2^{\circ} \text { e } 3^{\circ} \\
\text { anos do ensino } \\
\text { fundamental }\end{array}$ \\
\hline $\begin{array}{l}\text { Brincadeiras } \\
\text { de sucata }\end{array}$ & $\begin{array}{l}\text { Construir diversos tipos } \\
\text { de brinquedos utilizando } \\
\text { materiais recicláveis } \\
\text { (pet, rolinhos de papel } \\
\text { higiênico etc.) }\end{array}$ & $\begin{array}{l}\text { Alunos do } 1^{\circ} \text { ao } \\
5^{\circ} \text { ano do ensino } \\
\text { fundamental e pais }\end{array}$ \\
\hline $\begin{array}{l}\text { Incentivar a } \\
\text { comunidade a } \\
\text { uma alimentação } \\
\text { saudável }\end{array}$ & $\begin{array}{l}\text { Incentivar a comunidade } \\
\text { em geral a dar continuidade } \\
\text { ao que a escola oferece, } \\
\text { como o cultivo de verduras e } \\
\text { legumes em casa }\end{array}$ & $\begin{array}{l}\text { Escola e } \\
\text { comunidade local }\end{array}$ \\
\hline $\begin{array}{l}\text { Reaproveitamento } \\
\text { dos resíduos } \\
\text { produzidos } \\
\text { dentro do } \\
\text { ambiente escolar }\end{array}$ & $\begin{array}{l}\text { Sensibilizar professores, } \\
\text { funcionários e alunos; } \\
\text { reaproveitar os resíduos para } \\
\text { outros fins; montar ações } \\
\text { com a equipe escolar }\end{array}$ & Equipe escolar \\
\hline $\begin{array}{l}\text { Conscientização } \\
\text { para a } \\
\text { sustentabilidade }\end{array}$ & $\begin{array}{l}\text { Despertar e mobilizar a } \\
\text { comunidade para novos } \\
\text { hábitos }\end{array}$ & $\begin{array}{l}\text { Equipe escolar } \\
\text { Público de baixa } \\
\text { renda, alunos do } \\
\text { ensino fundamental } \\
\text { e comunidade }\end{array}$ \\
\hline
\end{tabular}

O sexto encontro, "Mapeamento socioambiental", buscou desenvolver um olhar socioambiental sobre os problemas e as potencialidades das questões ambientais no ambiente escolar, com base na metodologia do estudo do meio. $\mathrm{O}$ estudo do meio foi proposto pela Escola Moderna (1912), fundada em São Paulo, inspirada na pedagogia libertária de Francisco Ferrer y Guardia (1849-1909), anarquista, criador da Escola Moderna de Barcelona (1901) [14]. É uma metodologia de ensino interdisciplinar que possibilita estudar as modificações do espaço no tempo, analisando sua marca na própria paisagem, realizando uma leitura do espaço humano e o encontro e confronto de visões, o que contribui para um fazer coletivo [19]. Essa proposta tem como etapa fundamental o trabalho de campo [21], por meio do qual é possível realizar um movimento de apreensão plural e abrangente do espaço social, físico, histórico, cultural, 
ambiental e econômico, potencializado pelos estudos anteriores (levantamento bibliográfico e planejamento da saída a campo) e posteriores ao campo (reflexão crítica sobre o espaço estudado) [18]. Por essas razões, o método do estudo do meio traz uma contribuição importante à educação para as questões ambientais [23]. Esse encontro desenvolveu duas etapas do estudo do meio: a preparação e a saída para o campo. Para a preparação, foram levantadas informações sobre o bairro Recanto das Orquídeas, com mapas, dados demográficos, urbanísticos e socioeconômicos e informações ambientais; depois foi definida a área de estudo e as subáreas de visita para quatro grupos distintos. Cada grupo desenhou seu objetivo e atividades em sua área de estudo, que envolveram observação, registro gráfico (desenhos e fotografias) e entrevistas (moradores, empregados, comerciantes, transeuntes, etc.), compondo seu "caderno de campo" para a realização do trabalho de campo (Figura 3 ).
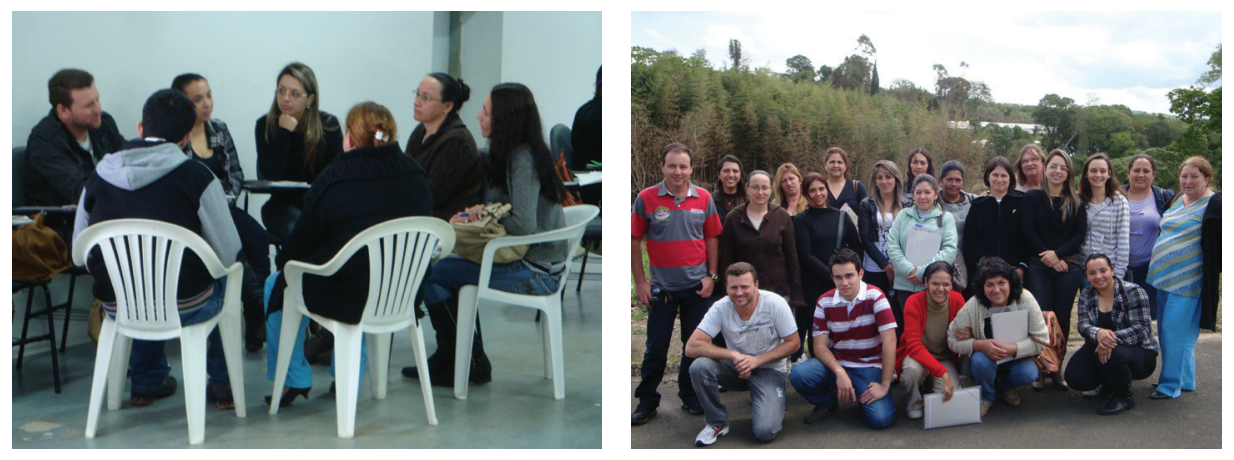

No sétimo encontro realizou-se a $3^{\text {a }}$ etapa do estudo do meio, a sistematização das informações e percepções advindas da atividade de campo. Para viabilizar esse trabalho aos participantes, foi proposto que cada um dos quatro grupos divididos para o trabalho de campo se reunisse separadamente. O resultado de cada grupo foi socializado no oitavo encontro. Foram apresentadas e confrontadas as opiniões e visões de cada grupo sobre o bairro visitado, colocando em evidência a complexidade das questões ambientais, que exige atitude de investigação atenta, curiosa, aberta à observação das múltiplas inter-relações e dimensões da realidade e muita disponibilidade e capacidade para o trabalho em equipe. Significa construir um conhecimento dialógico, ouvir os diferentes saberes, tanto os científicos quanto os outros saberes sociais (locais, tradicionais, das gerações, artísticos, poéticos etc); diagnosticar as situações presentes, mas não perder a dimensão da historicidade, ou seja, dar valor à história e à memória que se inscreve no ambiente e o constitui, simultaneamente, como paisagem natural e cultural. [5]

O oitavo encontro, dessa forma, buscou sintetizar os conteúdos abordados, realizar a "Avaliação" do curso e definir "Propostas futuras" com base em quatro reflexões:
Figura 3 - Estudo do meio: à esquerda, discussão preparatória sobre a área de estudo; à direita, atividade de campo para apreensão e reflexão sobre a relação ambiente-sociedade. 
1. O grupo de participantes do curso foi formado por vários atores da comunidade escolar. Qual seu comentário sobre essa experiência?

2. Os temas tratados contribuíram para a sua prática profissional?

3. Como você vê sua ação para a construção de uma sociedade sustentável?

4. Sugestões e críticas para futuros diálogos.

\section{LIÇÕES APRENDIDAS}

Os resultados do curso representam as lições aprendidas pelo grupo organizador e pelos participantes. Quanto aos pesquisadores, professores e monitores que planejaram e executaram o cronograma do curso, ficou a relevância do tema ambiental para refletir sobre a relação ambiente-sociedade e a qualidade de vida, além do papel da educação para se construir conhecimentos e práticas de sustentabilidade. Dar materialidade à cultura e extensão da universidade junto à sociedade também representou uma oportunidade de ampliar o campo de ação e reflexão do meio acadêmico junto a profissionais que cotidianamente lidam com desafios e encontram criativamente soluções para tais desafios. Esta ampliação não se dará apenas pelo diálogo, mas também pelo deslocamento físico para realização do curso na cidade de Ibiúna, o que deveria ser valorizado como estratégia para irradiar a responsabilidade da universidade com a sociedade e a relevância dos saberes locais para a construção do conhecimento acadêmico; passo representado pela vinda dos participantes até a Faculdade de Educação para entrega dos certificados. Para a equipe, foi um grande aprendizado, assim como para os participantes:

"Foi uma experiência maravilhosa, pois quando vamos fazer algo diferente no nosso cotidiano é muito difícil, mas quando nos reunimos para tratar de assuntos para o bem de todos, foi muito gratificante. Teve uma troca de experiências, onde todos aprenderam algo que ficou como experiência para ser usada no nosso dia-a-dia.”

"Foi uma experiência nova e interessante essa união da comunidade escolar, pois eu como merendeira nunca havia participado de cursos, sempre se lembram dos professores, não dos funcionários que compõem a comunidade escolar.”

"Sim, tudo o que adquirimos de conhecimento de uma forma ou de outra acabamos por utilizar em nossas práticas diárias. A partir do momento que temos novo conhecimento, passamos a ver o mundo a nossa volta com outro olhar."

Em termos concretos, o êxito pôde ser verificado pela permanência dos participantes. Todos os inscritos concluíram o curso. Observou-se que estavam não apenas interessados, mas também motivados, principalmente pelas diferentes técnicas 
pedagógicas que valorizaram a dimensão participativa e dialógica, dando voz aos participantes e valorizando o saber de cada um para uma construção coletiva de conhecimento; saber advindo de pessoas que desempenham funções diferentes e poucas vezes reconhecidas no espaço escolar. Agrupar diretores, vice-diretores, coordenadores, professores, secretários escolares, inspetores, merendeiras e auxiliares de serviços gerais foi um fato inédito aos participantes e à secretaria de educação do município. Além disso, oportunizar espaços de reflexão e produção, especialmente de projetos, coloca a relevância de se "plantar a semente" e "fazer germinar", possibilitando a saída dos participantes com um norte possível construído com suas próprias mãos.

\section{CONCLUSÕES}

O curso Diálogos da Universidade com a Comunidade Escolar Sobre Educação para a Sustentabilidade foi uma oportunidade de realizar atividades educativas na comunidade escolar e de aproximar seu contexto sociocultural e ambiental ao universo acadêmico. A proposta de construção de novas alternativas de extensão e ensino do curso gerou a necessidade de assumir outras maneiras de relacionamento entre profissionais, acadêmicos e comunidade, o que foi viabilizado pelo referencial teórico-metodológico da aprendizagem social. Em face aos problemas ambientais complexos que envolvem a responsabilidade de diferentes atores sociais, a articulação de saberes e o empoderamento dos indivíduos para pensarem sobre seu contexto e se mobilizarem em prol de mudanças são fundamentais para a construção de uma educação para a sustentabilidade, valorizando sobretudo os profissionais da educação envolvidos nessa tarefa.

\section{REFERENCIAS}

[1] BANDURA, A.; WALTERS, R.H. Social learning and personality development. New York: Holt Rinehart e Winston, 1963.

[2] BECK, U. Risk society: towards a new modernity. Los Angeles: London Sage, 1992.

[3] BRASIL. Lei $n^{\circ} 11.445$, de 5 de janeiro de 2007. Estabelece diretrizes nacionais para o saneamento básico e dá outras providências. Diário Oficial da União de 8.1.2007 e retificado em 11.1.2007, Brasília.

[4] BRASIL. Lei no 9.985, de 18 de julho de 200o. Regulamenta o art. 225, $\$ 10, incisos I, II, III e VII da Constituição Federal, institui o Sistema Nacional de Unidades de Conservação da Natureza e dá outras providências. Diário Oficial da União de 19.7.2000, Brasília.

[5] CARVALHO, I. C. de M. Educação Ambiental: a formação do sujeito ecológico. São Paulo: Cortez, 2004.

[6] FREIRE, P. Educação e mudança. Rio de Janeiro: Paz e Terra, 1979. 
[7] GÜNTHE, W. R. Formatação de indicadores de saneamento e saúde em comunidades isoladas. São Paulo: USP/FSP, 2008.

[8] HORTA, M. L. P.; GRUNBERG, E.; MONTEIRO, A. Q. Guia básico de educação patrimonial. Brasília: IPHAN, Museu Imperial, 1999.

[9] JACOBI, P. R. (coord.) Aprendizagem social e unidades de conservação: aprender juntos para cuidar dos recursos naturais. São Paulo: IEE/PROCAM, 2013. Disponível em: <http://goo.gl/pyKicH>. Acesso em o9 mai. 2014.

[10] JACOBI, P. R., FRANCO, M.I.G.C. Sustentabilidade, Participação e Aprendizagem Social. In: JACOBI, P.R. (coord.). Aprendizagem Social: Diálogos e Ferramentas Participativas - Aprender Juntos para Cuidar da Água. São Paulo: IEE/PROCAM, 2011.

[11] KEEN, M.; BROWN, V. A.; DYBALL, R. Social Learning: A New Approach to Environmental Management. In: : KEEN, M.; BROWN, V. A.; DYBALL, R. (eds). Social Learning in Environmental Management: Towards a Sustainable Future. London: Earthscan, 2005.

[12] KILVINGTON, M. J. Social Learning as a framework for building capacity to work, nov, 2007. Disponível em: < http://www.landcareresearch.co.nz/publications/researchpubs/Social_learning_review.pdf >. Acesso em 11 out. 2009.

[13] KILVINGTON, M. J. Building Capacity for Social Learning in Environmental Management. 2010. Tese (Doutorado em Filosofia), Lincoln University, Canterbury, Nova Zelândia, 2010. Disponível em: <http://goo.gl/Zde6Cc>. Acesso em 28 jan. 2013.

[14] LUIZETTO, F. V. Presença do anarquismo no Brasil: um estudo dos episódios literário e educacional - 1900/1920. 1984. Tese (Doutorado em História). UFSCar: São Carlos, 1984.

[15] MENESES, U. T. B. de. A história, cativa da memória? Para um mapeamento da memória no campo das Ciências Sociais. Revista do Instituto de Estudos Brasileiros, São Paulo, n.34, pp. 9-23, 1992. Disponível em: <http://www.ieb.usp.br/ publicacoes/doc/estagio_arquivo_2012_artigo_rieb3401_1348517923.pdf $>$. Acesso em 14 out. 2014. DOI: http://dx.doi.org/10.11606/issn.2316-901X.voi34p9-23

[16] NÉRICI, I. G. Metodologia de ensino: uma introdução. São Paulo, Atlas, 1981.

[17] PAZ, M.G.A. da. Jogo de Papéis: da Atuação ao Aprendizado. In: JACOBI, P. R. (coord.). Aprendizagem Social: Diálogos e Ferramentas Participativas Aprender Juntos para Cuidar da Água. São Paulo: IEE/PROCAM, 2011.

[18] PONTUSCHKA, N. N. O; PAGANELLI, T. I.; CACETE, N. H. Para ensinar e aprender Geografia. São Paulo, Cortez, 2007.

[19] PONTUSCHKA, N. N.(org) Um projeto... Tantas visões: a Educação Ambiental na escola pública. São Paulo: AGB, 1996.

[20] SACHS, W. La anatomía política del Desarrollo Sostenible. La gallina de los huevos de oro: Debate sobre el concepto de Desarrollo Sostenible. Colombia: Ecofondo-Cerec, 1996.

[21] SANTOS, V.M.N. Educar no ambiente: construção do olhar geocientífico e cidadania. São Paulo: Anablume, 2011. 
[22] SILVEIRA, F. L. A.; BEZERRA, M. Educação Patrimonial: perspectivas e dilemas. In: LIMA FILHO,M. F.; BELTRÃO, J. F. ECKERT, C.(orgs.). Antropologia e Patrimônio Cultural: Diálogos e Desafios Contemporâneos. Goiânia: ABA, 2007.

[23] SULAIMAN, S. N.; TRISTÃO, V.T. V. Estudo do meio: uma contribuição metodológica à educação ambiental. Fundação Universidade Federal do Rio Grande FURG, Rio Grande, RS. REMEA, v. 21, jul-dez de 2008. Disponível em: < http:// www.seer.furg.br/remea/article/view/3051/1733>. Acesso em 11 mai 2014.

[24] TOLEDO, R. F.; PELICIONI, M. C. F.; GIATTI, L. L.; BARREIRA, L. P., CUTOLO, S. A.; MUTTI, L. V.; ROCHA, A. A.; RIOS, L. Comunidade indígena na Amazônia: metodologia da pesquisa-ação em educação ambiental. $\mathbf{O}$ Mundo da Saúde, São Paulo, v. 30, pp.559-569, 2006. Disponível em: <http:// revistas.rcaap.pt/interaccoes/article/viewFile/382/337>. Acesso em 6 out. 2014.

\section{AGRADECIMENTOS}

Agradecemos o apoio da Prefeitura da Estância Turística de Ibiúna, da ONG Ação da Cidadania - Comitê Ibiúna/SP, da Cooperativa Agropecuária de Ibiúna (CAISP), da Hammnes Rotisserie e Confeitaria Ltda, da Cosfito Extratos Vegetais e aos monitores Diogo Braz Soares e Meire Araújo Almeida.

Samia nascimento sulaiman pesquisadora do Laboratório de Pesquisa e Práticas em Educação e Sustentabilidade (LAPPES-USP) e doutoranda da Faculdade de Educação da Universidade de São Paulo (FE-USP) - e-mail: samia.sulaiman@gmail.com

MARIA APARECIDA PIMENTEL TOLOZA RIBAS pesquisadora do Laboratório de Pesquisa e Práticas em Educação e Sustentabilidade (LAPPES-USP) e doutoranda da Faculdade de Educação da Universidade de São Paulo (FE-USP)

RENATA FERRAZ DE TOLEDO pós-doutora e pesquisadora do Laboratório de Pesquisa e Práticas em Educação e Sustentabilidade (LAPPES-USP) da Faculdade de Educação da Universidade de São Paulo (FE-USP)

ANA CRISTINA CHAGAS DOS ANJOS pesquisadora do Laboratório de Pesquisa e Práticas em Educação e Sustentabilidade (LAPPES-USP) e doutoranda da Faculdade de Educação da Universidade de São Paulo (FE-USP)

PEDRO ROBERTO JACOBI professor titular da Faculdade de Educação e do Instituto de Energia e Ambiente da Universidade de São Paulo (IEE-USP). Coordenador do Laboratório de Pesquisa e Práticas em Educação e Sustentabilidade (LAPPES-USP) da Universidade de São Paulo 